\title{
Ethical communication to guide climate policy decisions in the Arctic
}

\author{
Mona Behl \\ The Georgia Sea Grant College Program, The University of Georgia, Athens, Georgia, U.S.A \\ (mbehl@uga.edu.)
}

Received February 2016

ABSTRACT. Recent records of increasing temperature, melting of sea-ice, retreating glaciers, thawing permafrost, increasing sea levels, and increase in the frequency and intensity of extreme weather events provide clear evidence of global climate change, particularly in the Arctic. The impacts of climate change are not only environmental, but also influence social, economic, psychological, and political conditions in the region. The confluence of these conditions emphasises the need for improved communication of climate information and formulation of ethical responses to address changes in the Arctic. This review explores the meaning of ethical communication followed by an overview of the barriers to ethical communication including uncertainties related to climate change, and constructions of varying interpretations of climate change due to discipline-specific perspectives of science, journalism, and law, in the Arctic. The final section of this paper summarises key elements of ethical communication, and integration of ethical principles in formulating decision-making strategies to address climate change in the Arctic.

\section{Introduction}

Approximately four million people, inhabiting the Arctic, represent unique historical, cultural, and economical backgrounds. Arctic people have fewer adaptation options than those that are available elsewhere as their choices are limited by geography, economics, and culture. Due to their dependence upon, and close relationship with, the Arctic environment and its resources, indigenous peoples are among those least responsible, yet most impacted by changes in the Arctic (Bennett and others 2014). For these reasons, decision-making strategies must carefully consider the ethical tenets of responsibility, accountability and liability (for example Jamieson, 2007) in formulating ethical responses to address climate change in the Arctic.

Climate change is a complex issue due to its interdisciplinary effects, the significance of risks posed to societies and the environment, uncertainties associated with scientific evidence, and the scale and pace of future impacts. Levin and others (2012) characterise climate change as a 'super wicked problem' with four key features: time is running out; those who cause the problem also seek to provide a solution; the central authority needed to address it is weak or non-existent; and policy responses discount the future. Bray and von Storch (1999) view climate science as a case for 'postnormal science' (this term was first introduced by Funtowicz and Ravetz in 1991) due to its extension into the political and social realm, and the inherently large scientific uncertainty associated with it which is due to the lack of information, statistical variation, approximation, measurement error, disagreement about what is known, and subjective judgements.

Articulating relevant and timely climate information in a meaningful, understandable, and accurate manner is the most important first step to guide climate policy decisions in the Arctic. Leduc (2010) argues that climate change communication in indigenous communities may be useful for informing locals of the global, anthropogenic, and technological origins of climate change; and suggesting adaptation measures; as well as absolving small communities of responsibility for causing the problem. Experts engage in communicating climate change information due to the roles that they have earned (for example scientists), positions that they serve (for example science advisors, expert witnesses), or professions that they choose (for example professors, researchers, educators, science writers, etc.). Very often though, articulating climate information in the Arctic is limited to communicating climate science effectively, and informing the public about the societal implications of climate change. However, little attention is paid to determine if, and how, climate information is being used to form solutions and services that guide decision-making in the Arctic.

The goals of this review are to explore the meaning of ethical communication of climate change in the Arctic, to illuminate the ethical conundrums that experts face in communicating climate information that inspires climate solutions in the Arctic, and to identify a few mechanisms through which ethical principles can be integrated in the formulation of climate policy actions in the Arctic. Note that covering the expanse of philosophical, psychological, political science, or social science literature on ethical communication of climate science and decisionmaking is beyond the scope of this paper.

\section{Meaning of 'ethical communication of climate change'}

Generally speaking, 'ethics' refers to the fundamental set of moral values that govern human existence. These values could be placed in categories such as 'good or bad', 'right or wrong', 'just or unjust', etc. Ethical communication of climate change information refers to the moral aspects of interaction, either way, between an expert 
(communicator) and the audience (for example decisionmakers, local officials, jury, legislators, students, public, etc.). Ethical issues in such an interaction may arise when the expert seeks to present information, inform or educate the audience, demonstrate the existence and relevance of a societal issue, persuade them concerning the importance of an issue, influence decision-making, advocate a solution, or promote action. Access to timely, relevant, accurate, and understandable climate information is critical to guiding climate policy decisions in the Arctic. Ethical communication to guide decisionmaking in the Arctic requires clear articulation of climate change information, uncertainties and biases, formulation of solutions, and careful consideration of ethical implications of responses to climate change.

The intention of imparting information about climate change is to confer understanding about the Earth's climate system, increase awareness about the impacts of changing climate, foster a dialogue between scientists and the public, and inspire action for mitigation and adaptation. Since scientific research is largely funded by private and public funds, responsibility for dissemination of research results to broader audiences is also considered part of this support. Sustained engagement with the public on science also builds a sense of accountability, trust, and credibility on part of the scientists. A twoway flow of information between experts and the public leads to refinement and improved execution of research. Above all, it encourages humility and honesty about uncertainties in science. The formulation of solutions to climate change, in addition to discussion about impacts, is central to the ethical communication of climate change in the Arctic.

\section{Barriers to ethical communication of climate change}

Even though communication is central to conveying climate science information, both to experts and nonspecialists, there are several barriers that prevent effective communication of climate change in the Arctic. Moser (2010) summarises several challenges of climate change communication, namely, 'invisibility of causes, distant impacts, lack of immediacy and direct experience of the impacts, lack of gratification for taking action to mitigate consequences, disbelief in human's global influence, complexity and uncertainty, inadequate signals indicating the need for change, perceptual limits and self-interest.' One of the serious challenges that hinder action in response to climate change in the Arctic is the number of uncertainties involved. Scientific uncertainties may arise due to informational gaps in observational data, applicability and predictive capacity of climate models, statistical uncertainties, and epistemic uncertainties. Individual or collective action on climate change is also inhibited by ambiguity that arises when humans are uncertain about how to act in light of the causal link between human actions and climate change, or distinguish vulnerable societies from societies who contribute most to climate change. Climate change communication becomes even more problematic due to varying interpretations that can be constructed when climate change is discussed through discipline-specific perspectives of science, journalism, and law.

\section{Climate change through the perspectives of science}

Climate scientists disseminate the findings of their research primarily through publications in peer-reviewed journals that are usually subscription only and thus hardly reach beyond the scientific community. Scientists also engage in public discourse on climate change through public lectures, visitor programmes to museums and scientific laboratories, and various electronic means, to name a few dissemination pathways. However, many scientists view explicit science communication as being outside of their domain of responsibilities (Besley and Nisbet 2013). The structure and the internal reward system of academia is not conducive to encouraging bench scientists to engage with the public. This applies particularly in the USA but less so in other countries. The path to tenure is still peer-reviewed scholarship, not communication or outreach. Additionally, outstanding climate scientists can be poor communicators. Lack of proper training in science communication and incentives within academia further discourage climate scientists from having serious engagement with the public. The challenge of effectively and ethically communicating climate change is further exacerbated by shrinking funding for research and development, particularly in the United States (for example Hourihan 2015), which may tempt some scientists to exaggerate the importance of their work, hype uncertainty and consensus, and make biased statements. Experts can assist policymakers by quantifying risk associated with climate change, and articulating where, how and to what degree a risk exists. However, socio-cultural theories of risk contrast with the scientific model of risk and emphasise social and cultural contexts within which risk is understood and addressed. In his 'cultural cognition thesis,' Kahan (2009) suggests that individuals form their risk perceptions based on oftencontested personal views about what they believe benefits society.

\section{Climate change through the perspectives of media}

While the scientific community struggles to communicate about climate change, narratives of climate change are usually made ubiquitous by mass media. The advent of modern digital technology has led to an increase in the number of resources for the public to inform themselves on climate science and its implications on the society and the environment. On the other hand, the deluge of scientific information provided by the internet has led to challenges in discerning valid and relevant scientific content. Several experts have expressed concerns about the reduced quality of science reporting, inaccuracies, sensationalism, oversimplification, and politicisation of 
climate science information (for example Bell 1994; Hulme 2009). Access to digital media has encouraged many highly motivated individuals to report on climate science, albeit not always endowed with the adequate scientific accuracy. Discourse on climate change is made even more challenging if such individuals are not trained in journalistic practices of balance, objectivity, impartiality, and the norms of scientific discussions. As claimed by Dunwoody and Peters (1992), even those with training in journalism may use 'balance as a surrogate for validity checks' because of the lack sufficient time or expertise to properly investigate a story. When it comes to discussions regarding human contributions to climate change and actions required to address it, Boykoff and Boykoff (2004) assert that 'balancing of scientific findings and counterfindings' can often lead to an 'informational bias.'

\section{Climate change through the perspectives of law and policy}

Science not only crosses paths with journalism, but also with law and policy. Sarewitz (2004) argues that 'scientific inquiry is inherently and unavoidably subject to becoming politicized in environmental controversies' for three reasons: (1) 'science supplies contesting parties with their own bodies of relevant, legitimated facts about nature,' (2) the multidisciplinary nature of many environmental controversies may lead to 'competing valuebased political or ethical positions,' and (3) scientific uncertainty can be understood as 'the lack of coherence among competing scientific understandings, amplified by the various political, cultural, and institutional contexts within which science is carried out.' In the last decade, litigation involving weather and climate issues has increased (for example Hall 2011), and there is little likelihood that environmental litigation will abate. Discussion of science in the courtroom has its own challenges due to fundamental differences in the vocabulary and cultures of science and law. A number of familiar words have scientific definitions that differ from the vernacular (and legal definitions), for example, 'uncertainty', 'error', 'evidence', 'theory', 'bias', etc (see Hassol 2008). Scientific method is an iterative mechanism of falsification and self-correction, vetted by a rigorous peer review process that strives to ensure scientific merit, accuracy and quality of research. The nature of science is such that it encourages scepticism as much as it values consensus. Therefore, scientific arguments are built up out of evidence that is vulnerable to constant analysis and reassessment. On the other hand, lawyers start with a conclusion and seek the most compelling, convincing, and articulate evidence that supports it. There are also differences in how science and law treat standards of proof. Physical science uses quantitative data that is subject to statistical analysis. In the United States, the judicial standards of proof are lower than science - 'preponderance of the evidence' in civil trials and 'beyond reasonable doubt' in criminal trials.
The interaction of science with both journalism and law has demanded that science writers and judges assume a gate-keeping role in reviewing the admissibility of scientific evidence to the public and in the courtroom, respectively. Traditionally, this gate-keeping role enhanced the authority of science, whilst enhancing the status of science writers and judges. However, assessing the quality of scientific evidence without proper training in the scientific method has been a challenge for both science writers and judges.

\section{From barriers to solutions: integrating ethics to} formulate decision-making strategies in the Arctic

Ethical communication has three broad goals, to inform, to build relationships, and to persuade. It begins by defining the goals of the communication process, and can be achieved through honesty, accuracy, and placing climate science information into context, and addressing uncertainty, increasing public literacy about climate science, and through the availability of adequate incentives and resources of all involved.

Aristotle laid the groundwork for ethical communication by offering one of the earliest theories of communication in Rhetoric. He identified three critical elements of communication, ethos, pathos, and logos. Ethos is derived from the credibility of the speaker, pathos is derived from the emotion that is evoked in the audience, and logos is derived from the argument of a message. He illuminates the fact that interaction between a speaker and the audience is not restricted to mechanistic exchange of information, but requires credibility as well as trust on part of the speaker, and more engagement in the form of judgement on part of the audience. Garrett and Bird (2000) claim that the responsibility of a speaker is 'to be clear about what is expressed, and second to assess what is being perceived.' Johannesen and others (2008) emphasise the responsibility of the audience to be 'more discerning receivers and consumers of communication by encouraging ethical judgements of communication that are specifically focused and carefully considered.' An engaged audience is responsible for evaluating the climate change information that is being communicated to them. Additionally, the audience can assist in ethical communication by avoiding assumptions, acknowledging distinctions between disciplines and cultures, and by providing active feedback to the communicator. By actively engaging with the experts, the Arctic population (including local officials, rights- and stakeholders) can assist in devising solutions to address climate change in that region.

An important principle of ethical communication of climate change is determining the role that climate science experts want to play in the policy process. The path to objectivity in science does not involve scientists holding back their personal opinions, but actively making an effort to separate their personal values and prejudices from facts pertaining to climate change (Schneider 
2005). Pielke (2007) emphasises four ways in which scientists can engage with decision makers, namely: the pure scientist, science arbiter, issue advocate, and honest broker of policy alternatives. Determining how scientists choose to engage in the policy process has substantial implications for how science can influence policy decisions. Schneider (2005) argues that experts walk a tightrope because on the one hand they are charged with the responsibility 'to honestly report the range of plausible cases (what can happen?) and their associated subjective probability distributions (what are the odds?) and confidence levels. On the other hand, an expert could have personal opinion on what society ought to do with a particular risk assessment.' Experts could assist decision-makers by being clear and explicit about value-judgements, bias, and/or uncertainties associated with every response. Ballard and Lewandowsky (2015) emphasise the importance of communicating uncertainty 'in a way that improves people's understanding of climate change risks.' Sarewitz (2004) underscores the need to explore the value bases of disputes underlying environmental controversies through political means before science can play an effective role in solving problems.

In addition to technical knowledge, journalistic work must contribute to the ethical communication of climate change in the Arctic. Ward (2008) recommends several approaches for ethical media engagement in informing climate policy decisions. These approaches entail a sustained effort to reach out equally to all audiences (not just 'science-committed audience'), emphasising the science of climate change even in stories dominated by policy concerns, exploration of strategies to explain climate change, use of weight-of-evidence approach to represent divergent views on climate change, and striking an appropriate balance between local and global focus. Additionally, providing scientific training for journalists, and encouraging evidence-based reporting, can lead to meaningful and useful discussions about climate change.

Integral to the ethical communication of climate change in the Arctic is the culture and context in which the communication occurs. By understanding the knowledge needs of Arctic peoples, incorporating traditional knowledge, and carefully examining the implications of scientific research, scientists can make climate science more accessible and relevant for decision-making in the Arctic. Pidgeon and Fischhoff (2011) argue that instead of assuming what people know about climate science, the emphasis of climate change communication should be on providing useful climate information to people. Further, engaging Arctic indigenous communities in scientific research and translation of research can lead to the co-production of knowledge, including scientific and traditional knowledge. Co-generation of knowledge in turn increases credibility, reliability and ownership among individuals involved, and increases the likelihood for behavioural change. Information is also less likely to be contested in this process due to engagement and subsequent high legitimacy perceived by involved stake- and rights-holders. More importantly, information about climate change is placed into context and communicated within the cultural boundaries of indigenous communities, including applicable and usable knowledge for behavioural and societal change within and outside the Arctic. Integration of ethical implications of climate change by engaging the indigenous peoples of the Arctic can encourage reflection and learning between experts and non-specialists. Additionally, engagement with indigenous communities incorporates technical and traditional perspectives of achieving and maintaining sustainability in the Arctic.

Messengers are crucial to the ethical communication of climate change in the Arctic. Social scientists working on climate change recognise the persuasive influence that local messengers (Leiserowitz 2007) and credible messengers (Cole and Watrous 2007) can have in instigating action on climate change. Local leaders among Arctic people can serve as influential connectors in linking climate information to public policy actions. Identification of boundary organisations to communicate information that is seen as salient, credible, and legitimate in the world of action can further aid ethical decision-making process (for example Guston 1999; Guston 2001; Lemos and others 2014; Prokopy and others 2015).

Formulation of responses to address climate change in the Arctic requires ethical articulation of climate information, and careful integration of ethical principles to formulate decision-making strategies. Application of the 'precautionary principle' provides an important element of a value basis for formulation of ethical responses to climate change. From the standpoint of the precautionary principle, it is imperative to conduct focused, deliberate, and rigorous research to reduce scientific uncertainties related to climate change. It is also important to gain a better understanding of the nature of climate vulnerabilities faced by Arctic people, explore options that increase resiliency and help indigenous peoples adapt to climate change. Further, ethical decision-making must find a way to incorporate plurality of relevant values and interests. Renn and others (1993) suggest a 'participatory model for decision-making' that may be instructive to formulate ethical decision-making strategies in the Arctic. Participatory model for decision-making 'integrates technical expertise, values and concerns of stakeholder groups, and preferences of citizens into a procedural framework that enables generation of consensual policy decisions.' Integration of ethics in public policies related to changing Arctic also requires constant monitoring and evaluation of decision-making strategies that can be achieved by measuring the effectiveness of actions taken to address climate change in the Arctic, and adjusting decisionmaking strategies based on the desired outcomes.

\section{Conclusion}

As the Earth's climate system continues to change, society will turn to climate experts for managing risks and 
exploring opportunities in the most vulnerable parts of the world, particularly in the Arctic region. Changes in the Arctic calls for shared responsibility and collective action from various entities including experts, indigenous peoples, visiting scientists, journalists, stakeholders, and decision-makers, all of whom offer different but equal contributions to the decision-making process. The process of ethical communication of climate change in the Arctic must lead to effective responses to climate impacts. This process involves access to timely, and understandable information about climate impacts, coproduction of knowledge and solutions by experts and audiences, recognition of uncertainties and biases, careful consideration of the ethical consequences of different responses to climate change, and evaluation of decisionmaking actions.

\section{Financial support}

This study received no specific grant from any public funding agency, commercial or not-for-profit sectors.

\section{Conflicts of interest}

The author declares no conflicts of interest.

\section{Acknowledgements}

The author is thankful to Kathrin Keil, Wilfrid Greaves, and Jennifer Lukovich for their initial review of this paper. Any errors or omissions are of the author alone.

\section{References}

Ballard, T. and S. Lewandowsky. 2015. When, not if: the inescapability of an uncertain climate future. Philosophical Transactions of the Royal Society A 373(2055): 20140464.

Bell, A. 1994. Media (mis)communication on the science of Climate change. Public Understanding of Science: 3: 259275.

Besley, J. and M. Nisbet. 2013. How scientists view the public, the media and the political process. Public Understanding of Science 22(6): 644-659.

Bennett, T.M.B., N.G. Maynard, P. Cochran and others. 2014. Ch. 12: Indigenous peoples, lands, and resources. In: Melillo, J.M., T.C. Richmond and G.W. Yohe (editors). Climate change Impacts in the United States: the third national climate assessment. Washington D.C.: U.S. Global Change Research Program: 297-317.

Boykoff, M. and J. Boykoff. 2004. Balance as bias: global warming and the US prestige press. Global Environmental Change 14(2), 125-136.

Bray, D. and H. von Storch. 1999. Climate science: an empirical example of postnormal science. Bulletin of the American Meteorological Society 80, 439-455.

Cole, N. and S. Watrous. 2007. Across the great divide: supporting scientists as effective messengers in the public sphere. In: Moser, S.C. and L. Dilling (editors). Creating a climate for change: communicating climate change and facilitating social change. Cambridge: Cambridge University Press. 180-199.

Dunwoody, S. and H.P. Peters. 1992. Mass media coverage of technological and environmental risks. Public Understanding of Science 1 (2), 199-230.
Funtowicz, S. and Ravetz, J.R. 1991. A new scientific methodology for global environmental issues. In: Costanza, R. (editor). The ecological economics. New York: Columbia University Press: 137-152.

Garrett J.M., and S.J. Bird. 2000. Ethical issues in communicating science. Science and Engineering Ethics 6: 435-442.

Guston, D.H. 1999. Stabilizing the boundary between US politics and science: the role of the Office of Technology Transfer as a boundary organization. Social studies of science 29(1), 87111.

Guston, D.H. 2001. Boundary organizations in environmental policy and science: an introduction. Science, technology, and human values 26(4): 399-408.

Hall, S.S. 2011. Scientists on trial: At fault? Nature 477: 264269.

Hassol, S.J. 2008. Improving how scientists communicate about climate change. Eos Transactions AGU 89(11): 106-107, doi:10.1029/2008EO110002.

Hourihan, M. 2015. Historical trends in Federal R\&D. Washington D.C.: The American Association for the Advancement of Science. (AAAS Report XXXIX, Research and Development FY 2014): 23-28.

Hulme, M. 2009. Why we disagree about climate change: understanding controversy, inaction and opportunity. Cambridge: Cambridge University Press.

Jamieson, D. 2007. The moral and political challenges of climate change. In: Moser, S.C., and L. Dilling (editors). Creating a climate for change: communicating climate change and facilitating social change. Cambridge: Cambridge University Press: 475-482.

Johannesen, R.L., K.S. Valde and K.E. Whedbee. 2008. Ethics in human communication. Illinois: Waveland Press.

Kahan, D. 2009. Nanotechnology and society: the evolution of risk perceptions. Nature Nanotechnology 4: 705706.

Leduc, T.B. 2010. Climate, culture, change: Inuit and western dialogues with a warming north. Ottawa: University of Ottawa Press.

Levin, K., B. Cashore, S. Bernstein and other. 2012. Overcoming the tragedy of super wicked problems: constraining our future selves to ameliorate global climate change. Policy Sciences 45(2): 123-152.

Leiserowitz, A. 2007. Communicating the risks of global warming: American risk perceptions, affective images and interpretive communities. In: Moser, S. and L. Dilling (editors). Creating a climate for change: communicating climate change and facilitating social change. Cambridge: Cambridge University Press: 44-63.

Lemos, M.C., C.J. Kirchhoff, S.E. Kalafatis and others. 2014. Moving climate information off the shelf: boundary chains and the role of RISAs as adaptive organizations. Weather, Climate, and Society 6(2), 273-285.

Moser, S.C. 2010. Communicating climate change: history, challenges, process and future directions. Climate Change 1(1), 31-53.

Pidgeon, N.F. and B. Fischhoff. 2011. The role of social and decision sciences in communicating uncertain climate risks. Nature Climate Change 1: 35-41.

Pielke, J. and A, Roger. 2007. The honest broker: making sense of science in policy and politics. Cambridge: Cambridge University Press

Prokopy, L.S., J.S. Carlton, J.G. Arbuckle Jr. and others. 2015. Extension's role in disseminating information about climate change to agricultural stakeholders in the United States. Climatic Change 130(2): 261272. 
Renn, O., T. Webler, H. Rakel and others. 1993. Public participation in decision making: a three-step procedure. Policy Sciences 26(3): 189-214.

Sarewitz, D. 2004. How science makes environmental controversies worse. Environmental Science \& Policy 7(5): 385403.
Schneider, S.H. 2005b. Mediarology: the roles of citizens, journalists, and scientists in debunking climate change myths. URL: http://stephenschneider.stanford.edu/Mediarology/ Mediarology.html

Ward, S.J. 2008. Global journalism ethics: widening the conceptual base. Global Media Journal 1: 137. 